\title{
Neuronal nitric oxide synthase protects the pancreatic beta cell from glucolipotoxicity-induced endoplasmic reticulum stress and apoptosis
}

\author{
E. Bachar • Y. Ariav • E. Cerasi • N. Kaiser • \\ G. Leibowitz
}

Received: 2 March 2010 /Accepted: 28 May 2010 /Published online: 2 July 2010

(C) Springer-Verlag 2010

\begin{abstract}
Aims/hypothesis Cytokines stimulate nitric oxide production in pancreatic beta cells, leading to endoplasmic reticulum (ER) stress and apoptosis. Treatment of beta cells with glucose and NEFA induces nitric oxide synthase (NOS) as well as ER stress. However, the role of NO in glucolipotoxicity-induced ER stress in beta cells is not clear.

Methods We studied the effect of high glucose and palmitate levels on NOS isoform production in rat and Psammomys obesus islets and in insulinoma-1E beta cells. The effects of neuronal NOS (nNOS) inhibition by small interfering RNA or by $N^{\omega}$-nitro-L-arginine methyl ester (L-NAME) on beta cell function, ER stress and apoptosis under conditions of glucolipotoxicity were investigated.

Results Overnight incubation of rat and $P$. obesus islets at $22.2 \mathrm{mmol} / 1$ glucose with $0.5 \mathrm{mmol} / 1$ palmitate induced the production of nNOS but not inducible NOS (iNOS), in contrast with the robust stimulation of iNOS by cytokines. NOS inhibition by L-NAME did not prevent the decrease in glucose-stimulated insulin secretion and proinsulin biosynthesis or the depletion of islet insulin content observed under conditions of glucolipotoxicity. Moreover, treatment of beta cells with palmitate and L-NAME together resulted in marked activation of the IRE $1 \alpha$ and PERK pathways of the unfolded protein response. This was associated with increased JNK phosphorylation and apoptosis in islets and beta cells. Moreover, partial nNos knockdown increased
\end{abstract}

Electronic supplementary material The online version of this article (doi:10.1007/s00125-010-1833-6) contains supplementary material, which is available to authorised users.

E. Bachar $\cdot$ Y. Ariav $\cdot$ E. Cerasi $\cdot$ N. Kaiser $\cdot$ G. Leibowitz $(\bowtie)$ Endocrinology and Metabolism Service, Department of Medicine, Hadassah Hebrew University Medical Center,

P.O. Box 12000, Jerusalem 91120, Israel

e-mail: gleib@hadassah.org.il
JNK phosphorylation and CHOP production, leading to apoptosis.

Conclusions/interpretation In beta cells subjected to glucolipotoxic conditions, chronic inhibition of NOS exacerbates ER stress and activates JNK. Therefore, induction of nNOS is an adaptive response to glucolipotoxicity that protects beta cells from stress and apoptosis.

Keywords Apoptosis - Beta cells · Endoplasmic reticulum stress $\cdot$ Islets $\cdot$ Nitric oxide synthase $\cdot$ Type 2 diabetes

$\begin{array}{ll}\text { Abbreviations } \\ \text { CHOP } & \text { CCAAT/enhancer binding protein homologous } \\ & \text { protein } \\ \text { ECM } & \text { Extracellular matrix } \\ \text { ER } & \text { Endoplasmic reticulum } \\ \text { iNOS } & \text { Inducible nitric oxide synthase } \\ \text { INS-1E } & \text { Insulinoma 1E } \\ \text { IRE1 } & \text { Inositol requiring ER-to-nucleus signal kinase 1 } \\ \text { JNK } & \text { c-Jun N-terminal kinase } \\ \text { L-NAME } & N^{\omega} \text {-nitro-L-arginine methyl ester } \\ \text { NFKB } & \text { Nuclear factor } k \text { B } \\ \text { nNOS } & \text { Neuronal nitric oxide synthase } \\ \text { NO } & \text { Nitric oxide } \\ \text { NOS } & \text { Nitric oxide synthase } \\ \text { PERK } & \text { Protein kinase-like ER-associated kinase } \\ \text { UPR } & \text { Unfolded protein response } \\ \text { XBP1 } & \text { X-box binding protein-1 }\end{array}$

\section{Introduction}

In type 2 diabetes, elevated blood glucose and NEFA cause beta cell dysfunction and apoptosis, leading to exacerbation 
of diabetes by a process called glucolipotoxicity [1]. Glucolipotoxicity is believed to involve both oxidative and endoplasmic reticulum (ER) stresses [2-4]. The ER stress response, also called the unfolded protein response (UPR), is a complex signalling network that attempts to restore normal ER function by translation attenuation, degradation of misfolded proteins and increased protein folding capacity through augmented transcription and translocation of ER chaperones. UPR is initiated by three ER transmembrane sensor proteins: IRE1 (inositol requiring ER-to-nucleus signal kinase 1), the pancreatic ER kinase PERK (double-stranded RNA-activated protein kinase-like ER-associated kinase) and activating transcription factor 6 [5-7]. Sustained activation of the UPR may lead to cell death through activation of apoptotic signals by c-Jun N-terminal kinase (JNK, downstream to IRE1 $\alpha$ ) and CCAAT/enhancer binding protein homologous protein (CHOP, downstream to PERK) [3, 8, 9].

NEFAs, mainly palmitate, are potent inducers of ER stress in beta cells [3,10-12]. We have previously shown that glucose amplifies NEFA-induced ER stress through activation of the mammalian target of rapamycin complex 1 (mTORC1), which leads to apoptosis by activating JNK [13]. However, yet unknown additional mechanisms probably participate in glucolipotoxic ER stress.

Nitric oxide (NO), a mediator of protein nitrosylation and reactive oxygen species, can interfere with protein disulphide bonding and thereby result in protein misfolding and ER stress $[14,15]$. Indeed, NO has been suggested to play an important role in stroke and brain ischaemiareperfusion injury by inducing ER stress [15]. Moreover, $\mathrm{NO}$ is an important mediator of beta cell cytokine toxicity in type 1 diabetes, with induction of ER stress and apoptosis $[16,17]$.

Several studies have suggested that exposure of islets to high glucose or NEFA levels induces production of inducible nitric oxide synthase (iNOS), causing attenuation of the insulin response to glucose [18-22]. Thus, iNOS-dependent NO generation with subsequent induction of ER stress could be the common denominator of beta cell apoptosis induced by inflammatory cytokines and glucolipotoxicity. Nevertheless, it has not yet been shown convincingly that NO production is the cause of beta cell dysfunction and apoptosis during glucolipotoxicity. Moreover, other investigators have failed to find iNos (also known as Nos2) mRNA expression, nitrite production or activation of the nuclear factor $\mathrm{KB}(\mathrm{NF} \kappa \mathrm{B})$ pathway, an important mediator of cytokine-induced beta cell apoptosis, in rat beta cells treated with NEFA [23-25]. Therefore, the role of $\mathrm{NO}$ as a mediator of beta cell glucolipotoxicity remains controversial.

This motivated us to study the effects of glucose and palmitate on the production of different NOS isoforms in both rat and Psammomys obesus islets. P. obesus is a gerbil model of type 2 diabetes mellitus characterised by increased susceptibility to beta cell dysfunction and apoptosis in response to high glucose and NEFA levels, as found in islets of patients with type 2 diabetes [26]. We [27] and others [19] have previously shown that NO is a negative regulator of insulin secretion and that short-term NOS inhibition amplifies the response to acute stimulation by glucose and mitochondrial fuels. In the present study we describe the effects of pharmacological and genetic inhibition of neuronal nitric oxide synthase (nNOS) on beta cell function, ER stress and apoptosis under conditions of glucolipotoxicity.

\section{Methods}

Islet isolation and beta cell line culture Diabetes-prone P. obesus (Hebrew University Colony; Harlan, Jerusalem, Israel) aged 2.5-3.5 months were fed a low-energy $(9.96 \mathrm{~kJ} / \mathrm{g})$ diet (Koffolk, Petach-Tikva, Israel), which maintains normoglycaemia $(3-5 \mathrm{mmol} / 1$ in this species). Islets were isolated from normoglycaemic $P$. obesus and Wistar rats (Harlan, Jerusalem, Israel) by collagenase digestion (Collagenase P; Roche Diagnostics, Mannheim, Germany) as described [28], and used after repeated washes with Hanks' balanced salt solution. Islets were either incubated in suspension for $16 \mathrm{~h}$ or cultured in RPMI 1640 medium (Biological Industries, Beit-Haemek, Israel) with $10 \%$ fetal bovine serum, $100 \mathrm{U} / \mathrm{ml}$ penicillin, $100 \mu \mathrm{g} / \mathrm{ml}$ streptomycin and $2 \mathrm{mmol} / \mathrm{l} \mathrm{L}$-glutamine (Biological Industries) on extracellular matrix (ECM)-coated plates (Novamed, Jerusalem, Israel) [28] for 5 days at different glucose concentrations with and without $0.5 \mathrm{mmol} / \mathrm{l}$ palmitate, as indicated. Insulinoma 1E (INS-1E) beta cells were grown in RPMI 1640 medium supplemented with $10 \%$ fetal bovine serum, $1 \mathrm{mmol} / \mathrm{l}$ sodium pyruvate, $2 \mathrm{mmol} / 1 \mathrm{~L}$-glutamine, $10 \mathrm{mmol} / 1$ HEPES, $0.05 \mathrm{mmol} / 1$ 2-mercaptoethanol, $100 \mathrm{U} / \mathrm{ml}$ penicillin and $100 \mu \mathrm{g} / \mathrm{ml}$ streptomycin. Animal use was approved by the Institutional Animal Care and Use Committee of the Hebrew University and the Hadassah Medical Organization.

Experimental methods INS-1E cells and rat and P. obesus islets were incubated in RPMI medium with $0.55 \%$ (wt/vol.) BSA with or without palmitate at various glucose concentrations for different periods of time, as indicated in the figure legends. The palmitate-BSA solution was prepared as described [29]. Briefly, the sodium salt of palmitic acid was dissolved at a concentration of $10 \mathrm{mmol} / \mathrm{l}$ in $11 \% \mathrm{BSA}$ in a shaking water-bath at $37^{\circ} \mathrm{C}$ for $16 \mathrm{~h}$. The BSA that was used for solubilisation of palmitate was free of fatty acids and endotoxins. The $\mathrm{pH}$ of the solution was adjusted to 7.4 with $1 \mathrm{mmol} / \mathrm{l} \mathrm{NaOH}$, then filtered through a $0.2 \mu \mathrm{m}$ filter and 
stored at $-20^{\circ} \mathrm{C}$. The palmitate-BSA solution was diluted $1: 20$ in the incubation medium, the molar ratio of palmitate to BSA being $6: 1$. The effects of NOS inhibition on beta cell function, stress and apoptosis were studied by treating INS$1 \mathrm{E}$ cells and islets with 1 and $10 \mathrm{mmol} / \mathrm{l}$ of the NOS inhibitor $N^{\omega}$-nitro-L-arginine methyl ester (L-NAME) for different periods of time or by $n$ Nos knockdown. In part of the experiments, a cytokine cocktail (IL- $1 \beta 1 \times 10^{3} \mathrm{U} / \mu \mathrm{l}$, $\mathrm{TNF} \propto 500 \mathrm{U} / \mu \mathrm{l}, \mathrm{IFN} \gamma 1 \times 10^{3} \mathrm{U} / \mu \mathrm{l}$; PeproTech, Rocky Hill, NJ, USA) was used as positive control. All reagents were purchased from Sigma (Rehovot, Israel).

nNos knockdown nNos knockdown was performed by transient transfection of small interfering RNA oligos for $n N o s$ into INS-1E cells, which were plated in 24 well plates and grown overnight to approximately $70 \%$ confluence. Transfection was performed in serum-free RPMI medium using Lipofectamine (Invitrogen, Philadelphia, PA, USA) according to the manufacturer's instructions. The sequence targeted corresponded to bases 3323-3345 of the nNos mRNA (accession number NM_052799). The sense and antisense oligonucleotides were 5'-CGAGGACCUCGU GAAUGCACUCAUU and 5'-AAUGAGUGCAUUCACG AGGUCCUCG, respectively. Six hours after transfection the medium was replaced, and after an additional $24 \mathrm{~h}$ the cells were incubated overnight at different glucose concentrations with and without palmitate followed by extraction and analysis for the production of nNOS and different stress markers and for beta cell apoptosis.

Insulin secretion and proinsulin biosynthesis Groups of 25 islets were cultured on ECM-coated plates for 5 days with treatments as indicated. Insulin secretion of cultured islets was assessed at $24 \mathrm{~h}$ and 5 days by static $1 \mathrm{~h}$ incubations at 1.7 and $16.7 \mathrm{mmol} / \mathrm{l}$ glucose. Medium was collected at the end of the incubations, centrifuged and frozen at $-20^{\circ} \mathrm{C}$ pending insulin assay.

Proinsulin biosynthesis was studied by labelling islets in the centre of the plate in $25 \mu \mathrm{l}$ fresh KRB HEPES (KRBH)-BSA buffer [28]. The buffer contained different treatments at the same glucose concentration as for the chronic incubation and $0.925 \mathrm{MBq} \mathrm{L}-\left[2,3,4,5-{ }^{3} \mathrm{H}\right]$ leucine $\left(4.44 \times 10^{12} \mathrm{~Bq} / \mathrm{mmol}\right.$; ARC, St Louis, MO, USA). After a $15 \mathrm{~min}$ pulse at $37^{\circ} \mathrm{C}$, leucine incorporation was terminated by adding $1 \mathrm{ml}$ ice-cold glucose-free KRBH-BSA buffer, removal of the islets by scraping and rapid centrifugation. The islet pellet was subjected to immunoprecipitation as described [27].

Insulin assay Insulin immunoreactivity in $P$. obesus was determined using a human insulin RIA kit from Linco Research (St Charles, MO, USA) and rat insulin using a rat RIA kit (Linco Research).
Measurement of NOS activity and medium nitrites NOS activity was determined in rat islets and cerebellum using the NOSdetect assay kit (Stratagene, Cedar Creek, TX, USA) according to the manufacturer's instructions. The assay is based on the measurement of $\mathrm{L}-\left[{ }^{14} \mathrm{C}\right]$ citrulline, formed by NOS in equimolar concentration to NO. Islets were incubated at different glucose concentrations with and without $0.5 \mathrm{mmol} / \mathrm{l}$ palmitate for $16 \mathrm{~h}$, then washed and collected in $300 \mu$ ice-cold homogenisation buffer. The islets were sonicated and stored at $-80^{\circ} \mathrm{C}$ for subsequent measurement of NOS activity. Rat cerebellum homogenate was used as a positive control. Radioactivity was counted in Optiphase HiSafe scintillation cocktail (PerkinElmer, Waltham, MA, USA). Total NOS activity was determined by subtracting the background readings (with L-NAME) from the radioactive counts obtained without L-NAME. Calcium/ calmodulin is a cofactor for nNOS activity, whereas iNOS is calcium-independent. iNOS activity was determined by performing the NOS enzymatic reaction in the presence of the calcium chelator EGTA. This was subtracted from total NOS activity to give the nNOS activity [19]. Protein was determined with the Bradford method [30].

Nitrite production was measured in the incubation medium of INS-1E cells under different experimental conditions using the Griess reagent, as described [31]. Palmitate-supplemented medium was used as a blank.

Western blot analysis Protein production and phosphorylation were studied by western blotting using antibodies against iNOS (Sigma), nNOS, phospho-stress-activated protein kinase (SAPK)/JNK (Thr183/Tyr185), SAPK/JNK, phospho-c-JUN, total IRE1 $\alpha$, total and phospho-eIF2 $\alpha$, phospho-PERK, cleaved and non-cleaved caspase 3 (all from Cell Signaling Technology, Beverley, MA, USA), phospho-IRE1 $\alpha$ (kindly provided by F. Urano, University of Massachusetts, Boston, MA, USA), growth arrest- and DNA damage-inducible gene 153 (GADD153)/CHOP and GAPDH (Santa Cruz Biotechnology, Santa Cruz, CA, USA). Peroxidase-conjugated AffiniPure goat anti-rabbit and anti-mouse IgG from Jackson Immunoresearch Laboratories (West Grove, PA, USA) were used as secondary antibodies. Immunoreactive bands were visualised by chemiluminescence using ECL-Plus (Biological Industries, Rehovot, Israel). We used x-ray film densitometry for quantification (ImageMaster VDS-CL; Amersham Pharmacia Biotech, Uppsala, Sweden). Immunoblots were scanned and signals were quantified using TINA software (University of Manchester, Manchester, UK).

Quantitative real-time $R T-P C R$ RNA was extracted from INS-1E cells using TRI reagent (Biolab, Jerusalem, Israel) and reverse-transcribed using Moloney murine leukaemia virus reverse transcriptase (Promega, Madison, WI, USA). 
Quantitative real-time RT-PCR (qPCR) for spliced X-box binding protein-1 $(X b p 1)$ was performed on a Prism 7000 Sequence Detection System using the Power SYBR Green PCR Master Mix (Applied Biosystems, Foster City, CA, USA). Samples were analysed in triplicate and corrected for GAPDH. The following oligonucleotides were used for the PCR reaction: spliced Xbpl, forward 5'-GAGTCCGCAG CAGGTG-3', reverse 5'-GAAGAGGCAACAGCGTCAGA3'; Gadph, forward 5'-AGTTCAACGGCACAGTCAAG-3', reverse 5'-TACTCAGCACCAGCATCACC-3'.

Apoptosis ELISA assay Cells plated in 96-well plates were grown in RPMI 1640 containing $11.1 \mathrm{mmol} / \mathrm{l}$ glucose until they reached $70 \%$ confluence. They were then treated with $0.55 \%$ (wt/vol.) BSA with or without $0.5 \mathrm{mmol} / \mathrm{l}$ palmitate at 3.3 and $27.8 \mathrm{mmol} / 1$ glucose and L-NAME for $16 \mathrm{~h}$. The cells were lysed and oligonucleosomes in the cytosol, indicative of apoptosis-induced DNA degradation, were quantified using the Cell Death Detection ELISA Plus kit (Roche Diagnostics) according to the manufacturer's instructions.

Data presentation and statistical analysis Data shown are mean \pm SEM. Statistical significance of differences between groups was determined by one-way ANOVA followed by the Newman-Keuls test using the InStat statistical program (GraphPad Software, San Diego, CA,

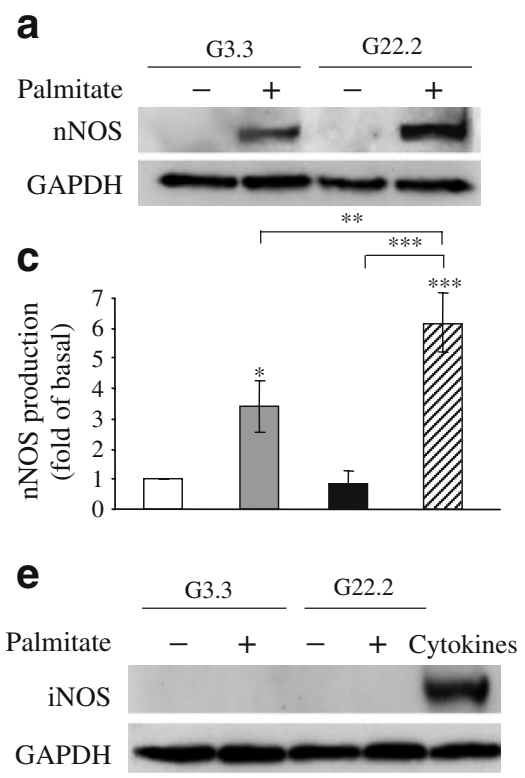

Fig. 1 NOS isoform production in rat and P. obesus islets was assessed by western blotting. P. obesus $(\mathbf{a}, \mathbf{c}, \mathbf{e})$ and rat $(\mathbf{b}, \mathbf{d}, \mathbf{f})$ islets were incubated at $3.3(\mathrm{G} 3.3)$ and $22.2(\mathrm{G} 22.2) \mathrm{mmol} / \mathrm{l}$ glucose with and without $0.5 \mathrm{mmol} / \mathrm{l}$ palmitate for $16 \mathrm{~h}$. Results are expressed as mean \pm SEM of three individual experiments. Extract of INS-1E cells
USA). A paired sample $t$ test was used when the difference between a reference (taken as 100\%) and test was analysed. A $p$ value of less than 0.05 was considered significant.

\section{Results}

Effects of glucose and palmitate on NOS isoform production and activity in islets NOS isoforms were studied in P. obesus and rat islet extracts following incubation for $16 \mathrm{~h}$ at $22.2 \mathrm{mmol} / \mathrm{l}$ glucose with and without $0.5 \mathrm{mmol} /$ 1 palmitate. Basal $(3.3 \mathrm{mmol} / \mathrm{l}$ glucose $)$ nNOS production was low in P. obesus islets; it was not increased in response to $22.2 \mathrm{mmol} / \mathrm{l}$ glucose either in rat or $P$. obesus islets. In contrast, $0.5 \mathrm{mmol} / \mathrm{l}$ palmitate induced nNOS at 22.2 and $3.3 \mathrm{mmol} / \mathrm{l}$ glucose in both species (Fig. 1a-d). Consistent with these findings, the effect of palmitate in INS-1E cells was concentration-dependent (see Electronic supplementary material [ESM] Fig. 1). In P. obesus islets treated with palmitate, nNOS production was higher at a high glucose concentration than at a low glucose concentration (6.5- and 3.4-fold increase in palmitate-treated P. obesus islets at 22.2 and $3.3 \mathrm{mmol} / 1$ glucose, respectively, compared with islets at $3.3 \mathrm{mmol} / 1$ glucose alone; Fig. 1a, c).

Whereas treatment with cytokines, as expected, resulted in robust induction of iNOS, there was no effect of palmitate on iNOS in rat or P. obesus islets (Fig. 1e, f).

b
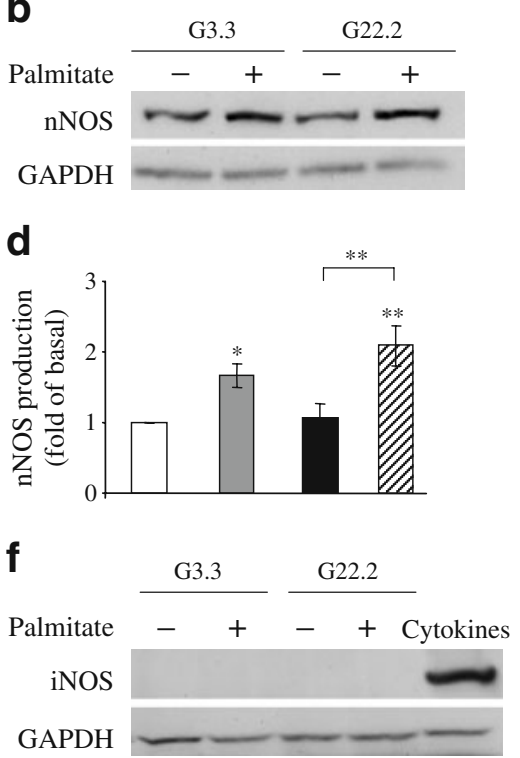

treated with a cocktail of cytokines $\left(1 \times 10^{3} \mathrm{U} / \mu \mathrm{IL}-1 \beta, 500 \mathrm{U} / \mu \mathrm{l}\right.$ $\mathrm{TNF} \alpha$ and $\left.1 \times 10^{3} \mathrm{U} / \mu \mathrm{l} \mathrm{IFN} \gamma\right)$ at $11.1 \mathrm{mmol} / 1$ glucose for $16 \mathrm{~h}$ was used as a positive control for iNOS. ${ }^{*} p<0.05, * * p<0.01,{ }^{* * *} p<0.001$ for the difference between the indicated groups or between these groups and untreated islets at $3.3 \mathrm{mmol} / \mathrm{l}$ glucose 
iNOS was also undetectable in INS-1E cells treated with palmitate (not shown).

Consistent with the lack of iNOS induction by palmitate, iNOS activity was undetected in islets incubated at $22.2 \mathrm{mmol} / \mathrm{l}$ glucose with palmitate (ESM Fig. 2a). Furthermore, total NOS activity of rat islets treated with palmitate was low: islets incubated at high glucose+palmitate concentrations showed $<1 \%$ NOS activity compared with rat cerebellar tissue. Moreover, there was only a small increase in nitrites in the medium of INS-1E cells treated with palmitate, whereas cytokines markedly increased nitrite production (ESM Fig. 2b).

Collectively, palmitate increased nNOS, but not iNOS, with a small increase in total NOS activity and nitrite production.

\section{Effect of NOS inhibition on beta cell function in islets exposed} to glucolipotoxicity The induction of nNOS by palmitate and high glucose was more pronounced in $P$. obesus than in rat islets. $P$. obesus islets are prone to develop beta cell dysfunction in response to high glucose and palmitate [26]. Therefore, to study the role of NOS, P. obesus islets were cultured on ECM-coated plates at $3.3 \mathrm{mmol} / \mathrm{l}$ glucose alone or $22.2 \mathrm{mmol} / \mathrm{l}$ glucose with and without $0.5 \mathrm{mmol} / \mathrm{l}$ palmitate and $10 \mathrm{mmol} / \mathrm{L} \mathrm{L}-\mathrm{NAME}$ for 5 days.

Under these conditions $22.2 \mathrm{mmol}$ glucose did not impair insulin secretion. Both basal and glucose-stimulated insulin secretion and proinsulin biosynthesis were higher at 22.2 than at $3.3 \mathrm{mmol} / 1$ glucose (Fig. 2a, b); however, the fold stimulation of insulin secretion was lower in islets cultured at $22.2 \mathrm{mmol} / 1$ than at $3.3 \mathrm{mmol} / 1$ glucose $(2.8-$ and 5.3 fold stimulation respectively, $p<0.001)$. Palmitate decreased glucose-stimulated insulin secretion by $37.3 \%$ at $24 \mathrm{~h}(p<0.01)$ and $27.5 \%$ at 5 days $(p<0.01$; Fig. $2 \mathrm{a}, \mathrm{b})$. Palmitate induced decreases of $70 \%$ in proinsulin biosynthesis and islet insulin content ( $p<0.001$ for both; Fig. 2c, d). L-NAME did not modify the attenuation of glucosestimulated insulin secretion and proinsulin biosynthesis, or the depletion of islet insulin content induced by palmitate.

In summary, NOS inhibition by L-NAME did not prevent the beta cell dysfunction induced by long-term treatment with palmitate and high glucose.

Effect of NOS inhibition on beta cell ER stress response to glucolipotoxicity Palmitate induces stress in pancreatic beta cells, leading to activation of JNK and consequently apoptosis [13, 32]. We first studied the effects of glucose, palmitate and L-NAME on JNK activation in P. obesus islets (Fig. 3a, b, c). JNK phosphorylation increased in islets treated with palmitate or L-NAME alone, although the effect was relatively small. Addition of both agents stressed the islets synergistically, with major augmentation of JNK phosphorylation at both 3.3 and $22.2 \mathrm{mmol} / \mathrm{l}$ glucose. There was a trend for higher JNK phosphorylation in islets treated with palmitate and L-NAME at $22.2 \mathrm{mmol} / \mathrm{l}$ glucose relative
Fig. 2 Effect of nNOS inhibition by L-NAME on insulin secretion (a, 24 h; b, 5 days), proinsulin (PI) biosynthesis (c) and insulin content (d) in $P$. obesus islets. Islets were isolated from normoglycaemic P. obesus and cultured on ECM-coated plates at $3.3(\mathrm{G} 3.3)$ and 22.2 (G22.2) $\mathrm{mmol} / \mathrm{l}$ glucose with and without $0.5 \mathrm{mmol} / 1$ palmitate and $10 \mathrm{mmol} / \mathrm{l} \mathrm{L}-\mathrm{NAME}$ for 5 days. Insulin secretion was analysed by static incubations at 1.7 (white bars) and 16.7 (black bars) $\mathrm{mmol} / \mathrm{l}$ glucose at $24 \mathrm{~h} \mathrm{(a)}$ and 5 days (b). Proinsulin biosynthesis was analysed at 5 days after a 15 min pulse with $\left[{ }^{3} \mathrm{H}\right]$ leucine, as described in the Methods.

Results are mean \pm SEM of nine individual experiments, each performed on islets pooled from three animals.

$*_{p}<0.05, * * p<0.01$,

$* * * p<0.001$ for the differences between the indicated groups or between these groups and control islets at $3.3 \mathrm{mmol} / 1$ glucose
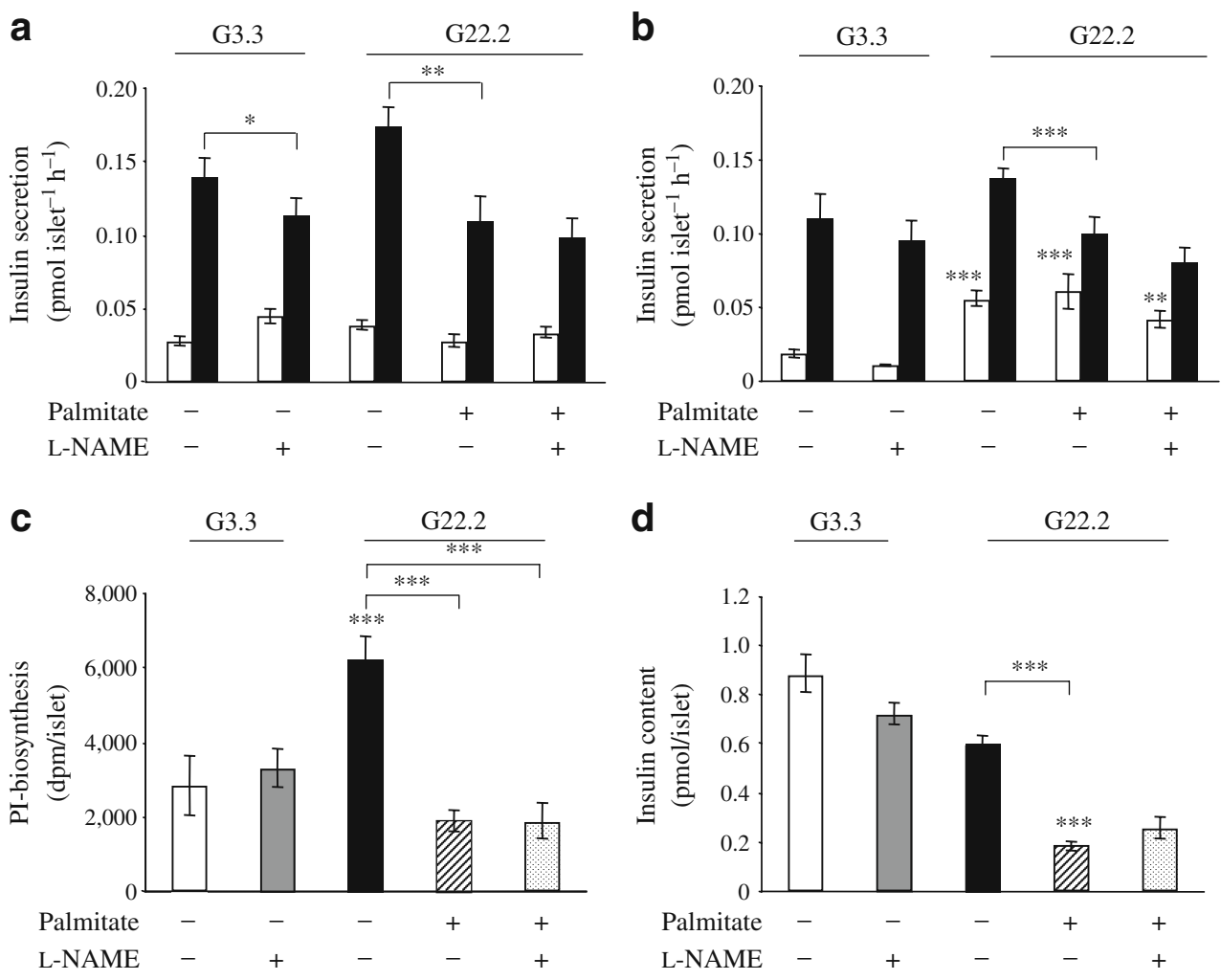
Fig. 3 Effect of nNOS inhibition by L-NAME on JNK expression and phosphorylation, and on apoptosis in P. obesus islets. $P$. obesus islets were incubated at 3.3 and $22.2 \mathrm{mmol} / 1$ glucose with and without $0.5 \mathrm{mmol} / \mathrm{l}$ palmitate and $10 \mathrm{mmol} / \mathrm{l} \mathrm{L}-\mathrm{NAME}$ for $16 \mathrm{~h}$. a, b, c Phosphorylated and total JNK were assessed by western blotting. d Apoptosis was analysed using an ELISA assay for oligonucleosomes. Results are expressed as mean \pm SEM of three individual experiments. ${ }^{*} p$ $<0.05, * * p<0.01, * * * p<0.001$ for the difference between the indicated groups or between these groups and control islets at $3.3 \mathrm{mmol} / \mathrm{l}$ glucose. AU, arbitrary units a

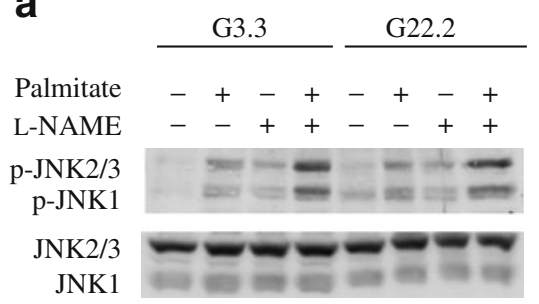

C

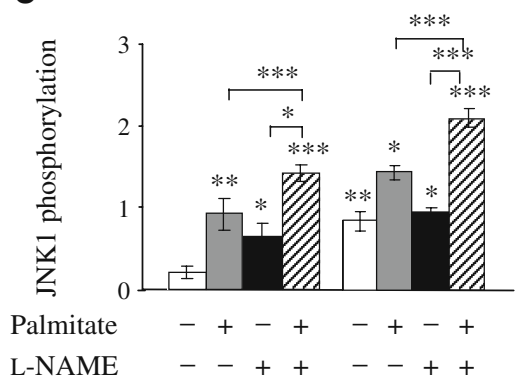

b

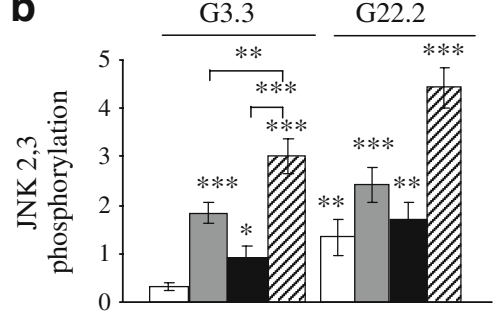

Palmitate $\quad-+-+-+-+$

L-NAME $\quad-\quad++--++$

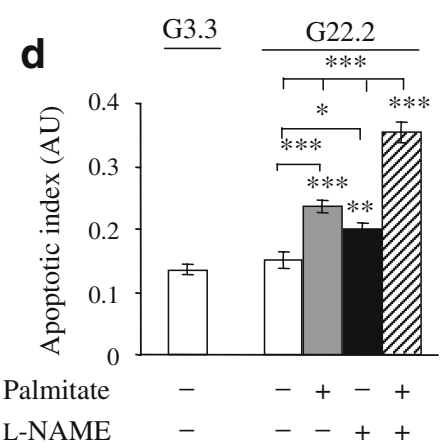

to $3.3 \mathrm{mmol} / \mathrm{l}$ glucose. JNK activation by L-NAME was associated with increased apoptosis (Fig. 3d). Thus, NOS inhibition increased, rather than decreased, JNK activation and apoptosis in islets exposed to glucolipotoxic conditions.

In INS-1E cells, knockdown of $n$ Nos induced a moderate (20-40\%) decrease in nNOS production (Fig. 4a, ESM Fig. 3a) and nitrite production (ESM Fig. 4). This resulted in increased JNK phosphorylation, CHOP production and augmented beta cell apoptosis (Fig. 4b-e, ESM Fig. 3).

JNK is a downstream target of the IRE1 $\alpha$ branch of the UPR. IRE $1 \alpha$ has a dual role during ER stress: (1) it acts as a kinase, phosphorylating apoptosis signalling kinase 1, thereby activating JNK; and (2) it cleaves the mRNA of the transcription factor XBP1. Spliced Xbpl is an important regulator of ER function [33, 34]. To further characterise the effects of NOS inhibition on the IRE1 $\alpha$ pathway, we analysed IRE1 $\alpha$ production and phosphorylation and Xbpl splicing in INS-1E beta cells incubated with palmitate and L-NAME at different glucose concentrations (Fig. 5 and ESM Fig. 5). Palmitate increased IRE1 $\alpha$ level and phosphorylation, JNK and levels of c-JUN phosphorylation (Fig. 5a-c) and spliced Xbpl (Fig. 5d). L-NAME modestly increased the level of ER stress markers at both 3.3 and $27.8 \mathrm{mmol} / \mathrm{l}$ glucose. However, treatment with palmitate and L-NAME together markedly increased spliced $X b p 1$ levels and JNK and c-JUN phosphorylation, indicating further stimulation of the IRE $1 \propto$ pathway.

We then studied the effects of glucose, palmitate and L-NAME on the PERK-eIF $2 \alpha$-CHOP branch of the UPR (Fig. 6, ESM Fig. 5). Similarly, L-NAME increased PERK, eIF $2 \alpha$ phosphorylation and CHOP level and amplified stimulation of eIF $2 \alpha$ and CHOP by palmitate.
Consistent with our previous report [13], we found that high glucose amplified the activation by palmitate of IRE $1 \alpha$, JNK and c-JUN and the level of CHOP. Moreover, the amplification of palmitate-induced ER stress by L-NAME was more pronounced at $27.8 \mathrm{mmol} / 1$ glucose than at $3.3 \mathrm{mmol} / 1$ glucose (Figs 5 and 6).

Effect of NOS inhibition on beta cell apoptosis during glucolipotoxicity The activation of stress markers by palmitate and L-NAME was associated with increased apoptosis in islets and beta cells (Figs 3 and 7a). Treatment of INS-1E cells with palmitate and a low concentration ( $1 \mathrm{mmol} / \mathrm{l})$ of L-NAME increased beta cell apoptosis compared with cells incubated with palmitate or L-NAME alone. High glucose amplified the effects of palmitate and L-NAME on beta cell apoptosis: the rate of apoptosis induced by addition of both agents was 1.6-fold higher at $27.8 \mathrm{mmol} / \mathrm{l}$ than at $3.3 \mathrm{mmol} / \mathrm{l}$ glucose.

JNK inhibition reduces beta cell apoptosis under conditions of ER stress [13]. Indeed, we found that the JNK inhibitor SP600125 completely prevented palmitateinduced beta cell apoptosis and decreased apoptosis in response to palmitate+L-NAME (Fig. 7b).

Thus, nNOS inhibition in beta cells augments glucolipotoxicity-induced ER stress and apoptosis, at least in part through activation of JNK.

\section{Discussion}

The aim of this study was to investigate the potential role of $\mathrm{NO}$ as a mediator of beta cell ER stress and apoptosis under 
a

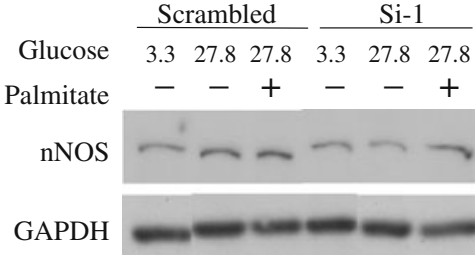

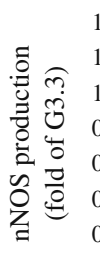

C

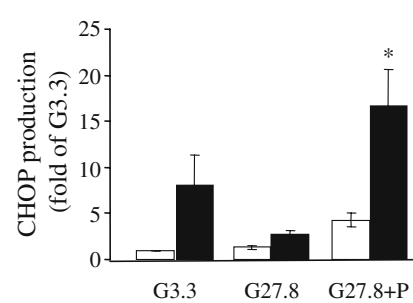

d

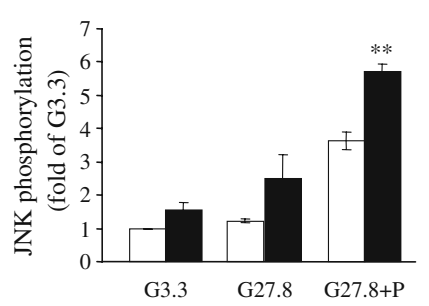

b

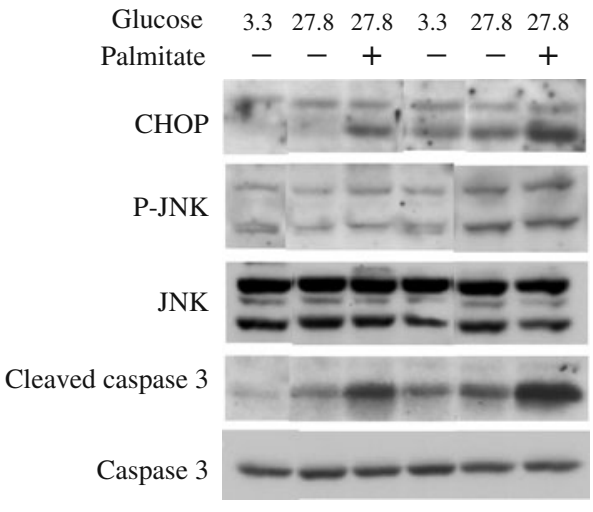

e

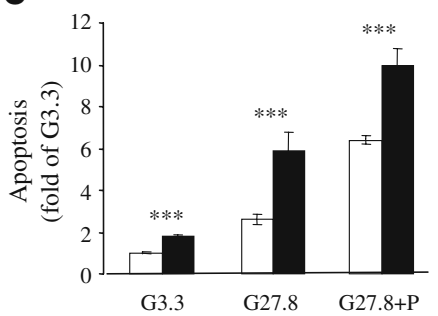

Fig. 4 Effects of nNos knockdown in INS-1E beta cells on nNOS production, stress markers and apoptosis. INS-1E cells were transfected with RNAi oligos for nNOS (black bars) or with control, scrambled RNA oligos (white bars), as described in the Methods. The cells were then incubated for $16 \mathrm{~h}$ at 3.3 and $27.8 \mathrm{mmol} / \mathrm{l}$ glucose with and without $0.5 \mathrm{mmol} / \mathrm{l}$ palmitate $(\mathrm{P})$. a nNOS production analysed by western blotting. b-d Western blot analysis of CHOP production, phosphorylated and total JNK, cleaved caspase 3 and caspase 3 . Representative gels and quantification of nNOS production, JNK phosphorylation (normalised to total $\mathrm{JNK}$ ) and $\mathrm{CHOP}$ production (normalised to GAPDH) are shown as fold of G3.3. e Apoptosis was analysed using the apoptosis ELISA assay. Results are expressed as mean \pm SEM of at least three individual experiments. ${ }^{*} p<0.05,{ }^{* *} p<0.01,{ }^{* * *} p<0.001$ for the difference between similarly treated $n$ Nos knockdown and control groups

peroxide levels [35]. Similarly, treatment of human islets with NEFA did not affect $i N O S$ expression [36]. Inhibition of NOS by L-NAME failed to restore beta cell function under conditions of glucolipotoxicity (Fig. 2) [35]. Thus, we do not believe that iNOS plays a significant role in glucolipotoxicity-induced beta cell dysfunction.

In contrast with the above, we found that palmitate induced nNOS production; therefore, we studied the role of NOS in the regulation of glucolipotoxicity-induced ER stress and apoptosis. Surprisingly, pharmacological or genetic inhibition of NOS by itself induced beta cell stress and apoptosis and amplified the stress response to palmitate, the effect being more pronounced at a high glucose concentration. Moreover, a modest degree of inhibition of $n N o s$ by small interfering RNA was sufficient to worsen beta cell stress and apoptosis. Similar results were obtained using two different small interfering RNA sequences (Fig. 4, ESM Fig. 3), suggesting that the pro-apoptotic effect of $n N o s$ knockdown results from nNOS inhibition rather than being an off-target effect. nNos knockdown induced beta cell stress and apoptosis even in the presence of a small decrease in nitrite production. NO measurements increase iNos gene expression [24], intracellular NO or 
Fig. 5 Effect of nNOS inhibition by L-NAME on IRE1 $\alpha$ pathway activation in INS-1E beta cells. INS-1E cells were incubated at 3.3 and 27.8 $\mathrm{mmol} / 1$ glucose with and without $0.5 \mathrm{mmol} / 1$ palmitate and 1 or $10 \mathrm{mmol} / 1 \mathrm{~L}-\mathrm{NAME}$ for $16 \mathrm{~h}$. a Representative gels showing phosphorylated and total IRE1 $\alpha$, phospho-c-JUN, phosphorylated and total JNK, and GAPDH. Quantification of JNK (b) and c-JUN (c) phosphorylation normalised to total JNK, shown as fold of G3.3.

d Spliced Xbpl levels assessed by quantitative RT-PCR. Each experiment was performed in triplicate. Results in $\mathbf{b}-\mathbf{d}$ are expressed as mean \pm SEM of three individual experiments. ${ }^{*} p<0.05, * * p<0.01$, $* * * p<0.001$ for the difference between the indicated groups or between these and untreated cells at the same glucose concentration

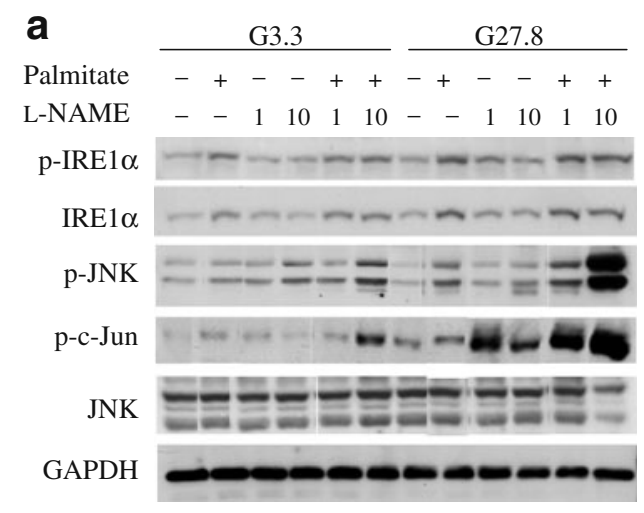

C

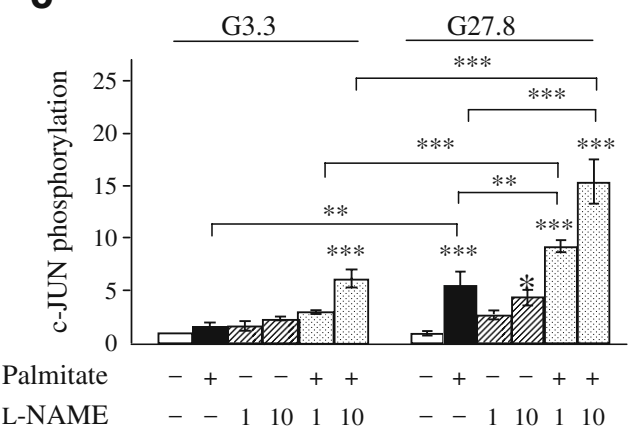

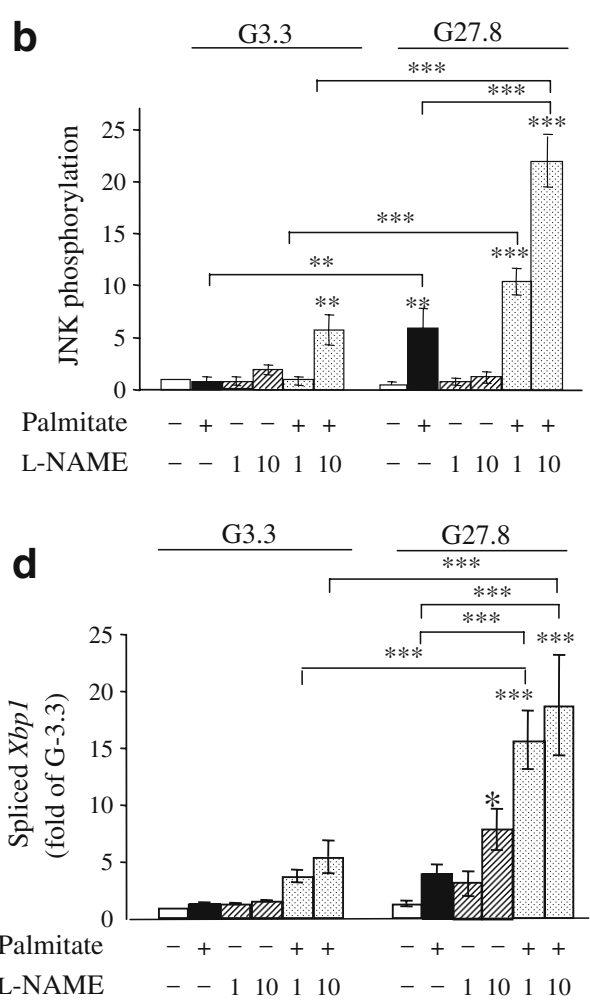

probably underestimate the effect of NOS inhibition on NO production due to its trapping in the cell by $S$-nitrosylation [37], as supported by the observation that the potent NOS inhibitor L-NAME also had a small effect on nitrite production. It is also possible that a minute decrease in NO, although not detected by the nitrite assay, is detrimental to the beta cell. Nonetheless, our findings indicate that nNOS activity is essential for beta cell survival, and its
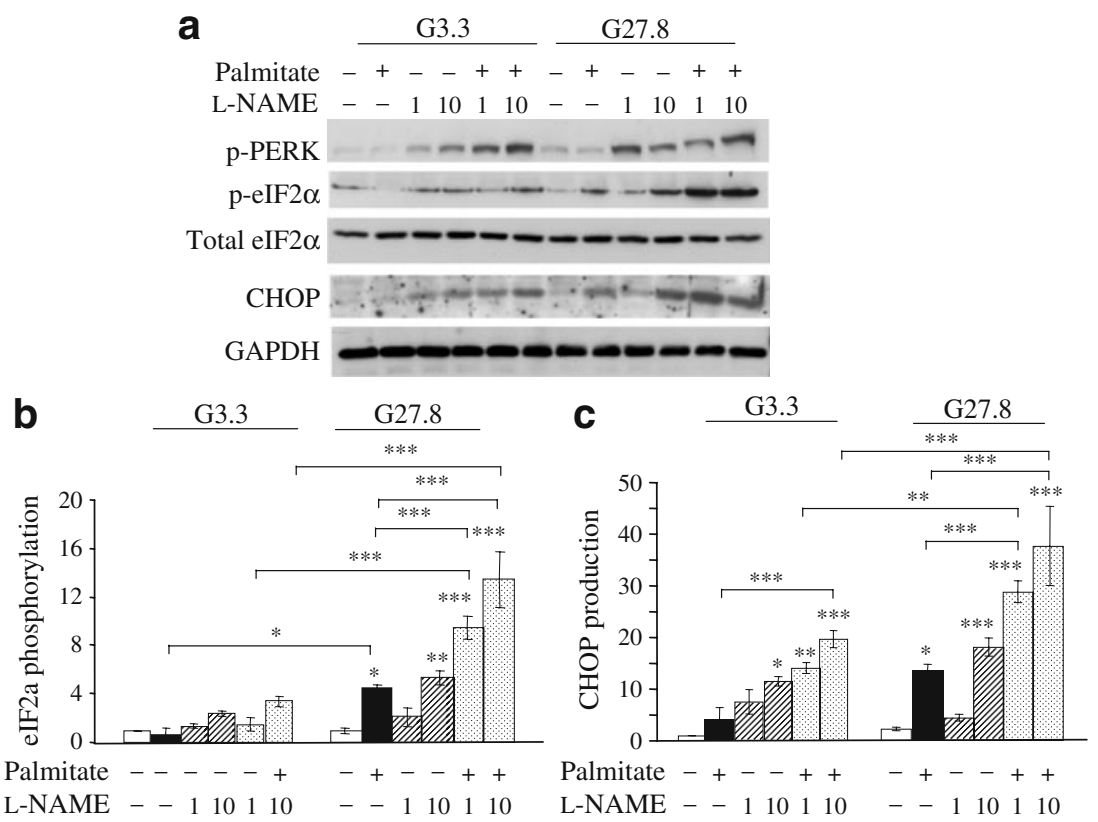

Fig. 6 Effect of nNOS inhibition by L-NAME on PERK pathway activation in INS-1E beta cells. INS-1E cells were incubated at 3.3 and $27.8 \mathrm{mmol} / 1$ glucose with and without $0.5 \mathrm{mmol} / \mathrm{l}$ palmitate and 1 or $10 \mathrm{mmol} / 1 \mathrm{~L}-\mathrm{NAME}$ for $16 \mathrm{~h}$. a Representative gels showing phosphorylated PERK (p-PERK), phosphorylated and total eIF2 $\alpha$, CHOP and GAPDH levels. Quantification of eIF $2 \alpha$ phosphorylation

normalised to total eIF2 $\alpha$ (b) and of CHOP normalised to GAPDH, (c) shown as fold of G3.3. Results are expressed as mean \pm SEM of three individual experiments. ${ }^{*} p<0.05,{ }^{*} p<0.01, * * * p<0.001$ for the difference between the indicated groups or between these and untreated cells at the same glucose concentration 

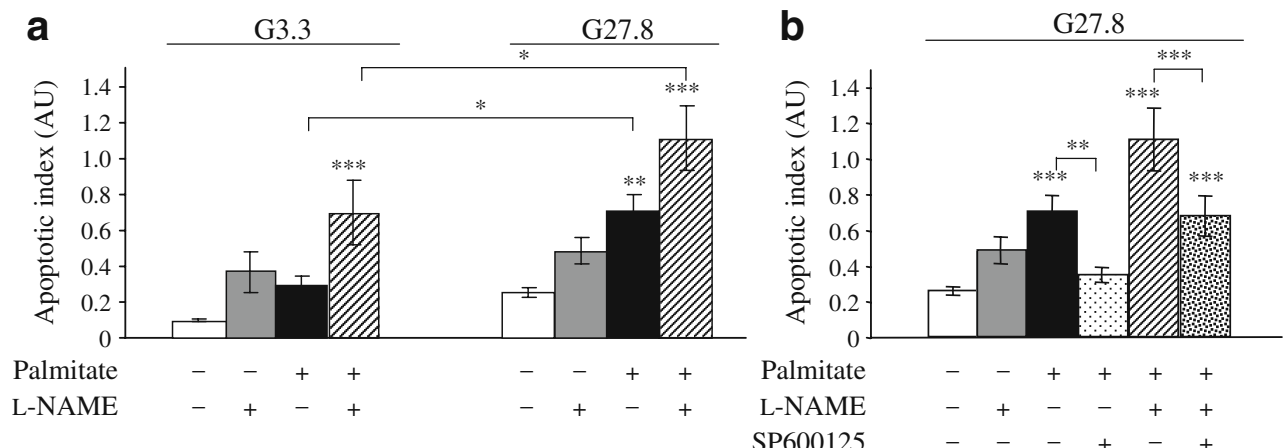

Fig. 7 Effect of pharmacological inhibition of nNOS and JNK on glucose- and palmitate-induced beta cell apoptosis. a INS-1E cells were incubated for $16 \mathrm{~h}$ at 3.3 and $27.8 \mathrm{mmol} / 1$ glucose with and without $0.5 \mathrm{mmol} / 1$ palmitate and $1 \mathrm{mmol} / 1 \mathrm{~L}-\mathrm{NAME}$. Apoptosis was assessed using the Cell Death Detection ELISA Plus kit. b INS-1E cells were incubated for $16 \mathrm{~h}$ at $27.8 \mathrm{mmol} / \mathrm{l}$ glucose with and without $0.5 \mathrm{mmol} / 1$ palmitate, $1 \mathrm{mmol} / 1 \mathrm{~L}-\mathrm{NAME}$ and $20 \mathrm{nmol} / 1$ of the JNK

upregulation in islets exposed to glucolipotoxicity is probably an important adaptive mechanism in the defence of beta cells against metabolic stress. Notably, treatment of cardiomyocytes with palmitate increased NO production via constitutive NOS, and its inhibition increased palmitate toxicity [38], consistent with the hypothesis that endogenous production of NO during metabolic stress is protective rather than noxious.

Nitric oxide may thus have a dual, opposing effect on beta cell survival depending on the spatial and temporal production of different NOS isoforms, the NO level achieved and the duration of exposure. NO can be scavenged by a rapid reaction with superoxide $\left(\mathrm{O}_{2}{ }^{-}\right)$to generate peroxynitrite $\left(\mathrm{ONOO}^{-}\right)$, which is a potent oxidant and the primary component of nitro-oxidative stress. At high concentrations, $\mathrm{ONOO}^{-}$can undergo cleavage to produce additional highly reactive oxidative species. This initiates a cascade of redox reactions which can trigger apoptosis [39]. Induction of iNOS by cytokines increases NO production massively, thereby leading to nitro-oxidative stress, which contributes to beta cell apoptosis in type 1 diabetes [40]. On the other hand, low levels of NO or of other nNOS product(s) may serve as antioxidant buffers, which dissipate reactive oxygen species. Notably, NOS activation may increase the production of the rate-limiting enzyme for glutathione synthesis and of genes involved in antioxidant defence [41]. Similarly, NO has a dual role in the regulation of neuronal cell survival, being neuroprotective through $S$ nitrosylation of NMDA receptors, and yet neurodestructive by the formation of peroxynitrite [42]. The dual role of NO in the regulation of beta cell survival is also demonstrated by its opposite effects on ER stress. While nNOS-derived NO alleviates the ER stress response to glucose and NEFA (Figs 4, 5, 6), excessive NO production by cytokines may indeed induce ER stress in beta cells [17]. The contribution inhibitor SP600125. The effect of JNK inhibition on apoptosis was analysed using the apoptosis ELISA assay. Quantification of three individual experiments, each performed in triplicate, is shown. ${ }^{*} p<0.05$, ${ }^{* *} p<0.01, * * * p<0.001$ for the difference between the indicated groups or between these and untreated cells at the same glucose concentration. AU, arbitrary units

of ER stress to cytokine-induced beta cell apoptosis is controversial [43]; nevertheless, nitrosylation of ERassociated calcium channels, such as sarcoendoplasmic reticulum $\mathrm{Ca}^{2+}$-ATPase (SERCA), and consequently calcium depletion in the ER and inactivation of protein disulfide isomerase may lead to protein misfolding [44-46], thereby contributing to beta cell dysfunction and apoptosis $[16,17]$.

Our data suggest a novel mechanism by which NOS protects the beta cell during glucolipotoxicity by attenuating the ER stress response. Indeed, NOS inhibition by LNAME amplified palmitate-stimulated ER stress in a concentration-dependent manner, as shown by its activation of the IRE $1 \alpha$ and PERK-eIF $2 \alpha-$ CHOP pathways of the UPR. Inducers of ER stress cause apoptosis through activation of JNK and CHOP. We found that L-NAME and $n N o s$ knockdown increased JNK/c-JUN phosphorylation and CHOP production. Consistent with our previous report [13], treatment with a pharmacological inhibitor of JNK prevented beta cell apoptosis under conditions of glucolipotoxicity and alleviated the deleterious effect of NOS inhibition under these conditions.

The recent report that incubation of INS-1 beta cells with a low concentration of diethylenetriamine nitric oxide adduct (DETA)/NO decreased apoptosis induced by the ER stressor thapsigargin, whereas a high concentration of this compound induced beta cell apoptosis [47], supports our conclusion that NO has a dual role in the regulation of beta cell survival and that low concentrations of $\mathrm{NO}$ are protective in the context of ER stress.

The precise mechanism by which NO regulates ER stress is unknown. Pharmacological induction of ER stress has been shown to increase endogenous NO production in the mouse insulinoma 6 (MIN6) beta cell line. This in turn augmented the expression of antioxidant genes, including endoplasmic reticulum oxidoreductin 1 (Erol) and protein 
disulphide isomerase $(P d i)$, which regulate oxidative protein folding in the ER, thereby reducing cellular stress [41].

Based on our results, we suggest the following paradigm for the role of nNOS in beta cell glucolipotoxicity: NEFAs stimulate the production of nNOS, but not iNOS, in islets. Although iNOS induction and subsequent excessive NO production may lead to ER stress and apoptosis, the small amounts of NO (and/or other byproducts) generated by nNOS during glucolipotoxicity attenuate the ER stress response in beta cells. Thus, induction of nNOS by palmitate is an important adaptive response to metabolic stress, protecting the beta cells from apoptosis.

Acknowledgements This study was supported by grants from the Israel Science Foundation.

Duality of interest The authors declare that there is no duality of interest associated with this manuscript.

\section{References}

1. Poitout V, Robertson RP (2007) Glucolipotoxicity: fuel excess and beta-cell dysfunction. Endocr Rev 29:351-366

2. Kaiser N, Leibowitz G (2009) Failure of beta-cell adaptation in type 2 diabetes: lessons from animal models. Front Biosci 14:1099-1115

3. Eizirik DL, Cardozo AK, Cnop M (2008) The role for endoplasmic reticulum stress in diabetes mellitus. Endocr Rev 29:42-61

4. Robertson R, Zhou H, Zhang T, Harmon JS (2007) Chronic oxidative stress as a mechanism for glucose toxicity of the beta cell in type 2 diabetes. Cell Biochem Biophys 48:139-146

5. Patil C, Walter $P$ (2001) Intracellular signaling from the endoplasmic reticulum to the nucleus: the unfolded protein response in yeast and mammals. Curr Opin Cell Biol 13:349-355

6. Ron D, Walter P (2007) Signal integration in the endoplasmic reticulum unfolded protein response. Nat Rev Mol Cell Biol 8:519-529

7. Marciniak SJ, Ron D (2006) Endoplasmic reticulum stress signaling in disease. Physiol Rev 86:1133-1149

8. Fonseca SG, Lipson KL, Urano F (2007) Endoplasmic reticulum stress signaling in pancreatic beta-cells. Antioxid Redox Signal 9:2335-2344

9. Ortsäter H, Sjöholm A (2007) A busy cell-endoplasmic reticulum stress in the pancreatic beta-cell. Mol Cell Endocrinol 277:1-5

10. Laybutt DR, Preston AM, Akerfeldt MC et al (2007) Endoplasmic reticulum stress contributes to beta cell apoptosis in type 2 diabetes. Diabetologia 50:752-563

11. Lai E, Bikopoulos G, Wheeler MB, Rozakis-Adcock M, Volchuk A (2008) Differential activation of ER stress and apoptosis in response to chronically elevated free fatty acids in pancreatic beta-cells. Am J Physiol Endocrinol Metab 294:E540-E550

12. Karaskov E, Scott C, Zhang L, Teodoro T, Ravazzola M, Volchuk A (2006) Chronic palmitate but not oleate exposure induces endoplasmic reticulum stress, which may contribute to INS-1 pancreatic beta-cell apoptosis. Endocrinology 147:3398-3407

13. Bachar E, Ariav Y, Ketzinel-Gilad M, Cerasi E, Kaiser N, Leibowitz G (2009) Glucose amplifies fatty acid-induced endo- plasmic reticulum stress in pancreatic beta-cells via activation of mTORC1. PLoS ONE 4:e4954

14. Kim I, Xu W, Reed JC (2008) Cell death and endoplasmic reticulum stress: disease relevance and therapeutic opportunities. Nat Rev Drug Discov 7:1013-1030

15. Gotoh T, Mori M (2006) Nitric oxide and endoplasmic reticulum stress. Arterioscler Thromb Vasc Biol 26:1439-1446

16. Oyadomari S, Takeda K, Takiguchi M et al (2001) Nitric oxideinduced apoptosis in pancreatic beta cells is mediated by the endoplasmic reticulum stress pathway. Proc Natl Acad Sci USA 98:10845-10850

17. Eizirik DL, Colli ML, Ortis F (2009) The role of inflammation in insulitis and beta-cell loss in type 1 diabetes. Nat Rev Endocrinol 5:219-226

18. Meidute Abaraviciene S, Lundquist I, Galvanovskis J, Flodgren E, Olde B, Salehi A (2008) Palmitate-induced beta-cell dysfunction is associated with excessive NO production and is reversed by thiazolidinedione-mediated inhibition of GPR40 transduction mechanisms. PLoS ONE 3:e2182

19. Henningsson R, Salehi A, Lundquist I (2002) Role of nitric oxide synthase isoforms in glucose-stimulated insulin release. Am J Physiol Cell Physiol 283:C296-C304

20. Qader SS, Jimenez-Feltstrom J, Ekelund M, Lundquist I, Salehi A (2007) Expression of islet inducible nitric oxide synthase and inhibition of glucose-stimulated insulin release after long-term lipid infusion in the rat is counteracted by PACAP27. Am J Physiol Endocrinol Metab 292:E1447-E1455

21. Salehi A, Ekelund M, Lundquist I (2003) Total parenteral nutrition-stimulated activity of inducible nitric oxide synthase in rat pancreatic islets is suppressed by glucagon-like peptide-1. Horm Metab Res 35:48-54

22. Salehi A, Meidute Abaraviciene S, Jimenez-Feltstrom J, Ostenson CG, Efendic S, Lundquist I (2008) Excessive islet NO generation in type 2 diabetic GK rats coincides with abnormal hormone secretion and is counteracted by GLP-1. PLoS ONE 3:e2165

23. Carlsson C, Borg LA, Welsh N (1999) Sodium palmitate induces partial mitochondrial uncoupling and reactive oxygen species in rat pancreatic islets in vitro. Endocrinology 140:3422-3428

24. Kharroubi I, Ladriere L, Cardozo AK, Dogusan Z, Cnop M, Eizirik DL (2004) Free fatty acids and cytokines induce pancreatic beta-cell apoptosis by different mechanisms: role of nuclear factor-kappaB and endoplasmic reticulum stress. Endocrinology 145:5087-5096

25. Cnop M, Welsh N, Jonas JC, Jörns A, Lenzen S, Eizirik DL (2005) Mechanisms of pancreatic beta-cell death in type 1 and type 2 diabetes: many differences, few similarities. Diabetes 54 (Suppl 2):S97-S107

26. Kaiser N, Nesher R, Donath MY et al (2005) Psammomys obesus, a model for environment-gene interactions in type 2 diabetes. Diabetes 54(Supp1 2):S137-S144

27. Attali V, Parnes M, Ariav Y, Cerasi E, Kaiser N, Leibowitz G (2006) Regulation of insulin secretion and proinsulin biosynthesis by succinate. Endocrinology 147:5110-5118

28. Kaiser N, Corcos AP, Tur-Sinai A, Ariav Y, Cerasi E (1988) Monolayer culture of adult rat pancreatic islets on extracellular matrix: long term maintenance of differentiated B cell function. Endocrinology 123:834-840

29. Maedler K, Oberholzer J, Bucher P, Spinas GA, Donath MY (2003) Monounsaturated fatty acids prevent the deleterious effects of palmitate and high glucose on human pancreatic beta-cell turnover and function. Diabetes 52:726-733

30. Bradford MM (1976) A rapid and sensitive method for the quantitation of microgram quantities of protein utilizing the principle of protein-dye binding. Anal Biochem 72:248-254 
31. Green LC, Wagner DA, Glogowski J, Skipper PL, Wishnok JS, Tannenbaum SR (1982) Analysis of nitrate, nitrite, and $\left[{ }^{15} \mathrm{~N}\right]$ nitrate in biological fluids. Anal Biochem 126:131-138

32. Cunha DA, Hekerman P, Ladriere L et al (2008) Initiation and execution of lipotoxic ER stress in pancreatic beta-cells. J Cell Sci 121:2308-2318

33. Calfon M, Zeng H, Urano F et al (2002) IRE1 couples endoplasmic reticulum load to secretory capacity by processing the XBP-1 mRNA. Nature 415:92-96

34. Lee AH, Iwakoshi NN, Glimcher LH (2003) XBP-1 regulates a subset of endoplasmic reticulum resident chaperone genes in the unfolded protein response. Mol Cell Biol 23:7448-7459

35. Moore PC, Ugas MA, Hagman DK, Parazzoli SD, Poitout V (2004) Evidence against the involvement of oxidative stress in fatty acid inhibition of insulin secretion. Diabetes 53:2610-2616

36. Lupi R, Dotta F, Marselli L et al (2002) Prolonged exposure to free fatty acids has cytostatic and pro-apoptotic effects on human pancreatic islets: evidence that beta-cell death is caspase mediated, partially dependent on ceramide pathway, and Bcl-2 regulated. Diabetes 51:1437-1442

37. Jaffrey SR, Erdjument-Bromage H, Ferris CD, Tempst P, Snyder SH (2001) Protein $S$-nitrosylation: a physiological signal for neuronal nitric oxide. Nat Cell Biol 3:193-197

38. Rabkin SW, Klassen SS (2008) Palmitate-induced NO production has a dual action to reduce cell death through $\mathrm{NO}$ and accentuate cell death through peroxynitrite formation. Prostaglandins Leukot Essent Fatty Acids 78:147-155

39. Pacher P, Beckman JS, Liaudet L (2007) Nitric oxide and peroxynitrite in health and disease. Physiol Rev 87:315-424
40. Storling J, Binzer J, Andersson AK et al (2005) Nitric oxide contributes to cytokine-induced apoptosis in pancreatic beta cells via potentiation of JNK activity and inhibition of Akt. Diabetologia 48:2039-2050

41. Kitiphongspattana K, Khan TA, Ishii-Schrade K, Roe MW, Philipson LH, Gaskins HR (2007) Protective role for nitric oxide during the endoplasmic reticulum stress response in pancreatic beta-cells. Am J Physiol Endocrinol Metab 292: E1543-E1554

42. Nakamura T, Lipton SA (2009) Cell death: protein misfolding and neurodegenerative diseases. Apoptosis 14:455-468

43. Akerfeldt MC, Howes J, Chan JY et al (2008) Cytokine-induced beta-cell death is independent of endoplasmic reticulum stress signaling. Diabetes 57:3034-3044

44. Xu L, Eu JP, Meissner G, Stamler JS (1998) Activation of the cardiac calcium release channel (ryanodine receptor) by poly-Snitrosylation. Science 279:234-237

45. Viner RI, Ferrington DA, Williams TD, Bigelow DJ, Schoneich C (1999) Protein modification during biological aging: selective tyrosine nitration of the SERCA2a isoform of the sarcoplasmic reticulum $\mathrm{Ca}^{2+}$-ATPase in skeletal muscle. Biochem $\mathrm{J}$ 340:657669

46. Uehara T, Nakamura T, Yao D et al (2006) S-nitrosylated proteindisulphide isomerase links protein misfolding to neurodegeneration. Nature 441:513-517

47. Noguchi A, Takada M, Nakayama K, Ishikawa T (2008) cGMPindependent anti-apoptotic effect of nitric oxide on thapsigargininduced apoptosis in the pancreatic beta-cell line INS-1. Life Sci $83: 865-870$ 